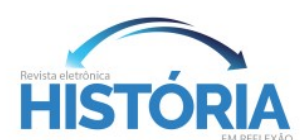

Dossiê: Ensino de História, História das Mulheres e Desigualdades Sociais no Brasil

\title{
PARTICIPAÇÃO FEMININA NA POLÍTICA E NA AÇÃO POPULAR: DO MARIANISMO AO CRISTOCENTRISMO NA AÇÃO CATÓLICA BRASILEIRA
}

\section{FEMALE PARTICIPATION IN POLITICS AND POPULAR ACTION: FROM MARIANISM TO CHRISTOCENTRISM IN BRAZILIAN CATHOLIC ACTION}

Camila de Jesus Silva ${ }^{1}$

\begin{abstract}
RESUMO: Na década de 1960, no Brasil, formaram-se diversas organizações da chamada Nova Esquerda. Entre todas essas organizações, a que mais admitira mulheres em seu quadro militante, inclusive em posições diretivas, foi a Ação Popular. Neste artigo procuramos investigar algumas causas da inclusão feminina nesse meio político, principalmente no que se refere aos elementos ideológicos e simbólicos adotados pela lgreja Católica até aquele momento. Uma de nossas hipóteses é que essa inserção deve-se à passagem ideológica do marianismo ao cristocentrismo, na Ação Católica Brasileira, desde 1935 até a primeira metade da década de 1960.
\end{abstract}

PALAVRAS-CHAVE: Mulheres. Ação Católica Brasileira. Ação Popular.

ABSTRACT: In the 1960s, in Brazil, several organizations of the called New Left were formed. Among all these organizations, the one that most admitted women in their militant position, including in positions of leadership, it was Popular Action. In this article we seek to investigate some causes of female inclusion in this political environment, mainly with regard to the ideological and symbolic elements adopted by the Catholic Church up to that time. One of our hypotheses justifies such insertion in the ideological passage from Marianism to Christocentrism, in Brazilian Catholic Action from 1935 until the first half of the 1960s.

KEYWORDS: Women. Brazilian Catholic Action. Popular Action.

Introdução

Nosso texto parte de um problema surgido em nossos trabalhos anteriores, mais especificamente da monografia As mulheres que lutaram contra a Ditadura Militar em Goiás: o caso da Ação Popular; e da dissertação de mestrado A Nova Esquerda e sua atuação regional: a Ação Popular em Goiás, que tratam, respectivamente, da experiência de mulheres que foram militantes da Ação Popular em Goiás e da história dessa organização de esquerda no estado. Em ambos os

\footnotetext{
${ }^{1}$ Mestre em História - Doutoranda - Programa de Pós Graduação em História - Universidade Federal de Goiás - PPGH/UFG - Brasil. Professora efetiva em SEDUC-MT -Secretaria de Estado de Educação do Mato Grosso. E-mail: camilajesilva@gmail.com.
} 


\section{HISTÓRIA}

Dossiê: Ensino de História, História das Mulheres e Desigualdades Sociais no Brasil

trabalhos pudemos perceber uma participação muito expressiva das mulheres, o que também é possível constatar em outros trabalhos sobre a AP publicados no país. É importante ressaltar a origem particular da Ação Popular, sendo uma organização da chamada Nova Esquerda que nasceu entre os meios estudantis da Ação Católica brasileira. Ao mesmo tempo, é preciso contextualizar a criação da AP em meio à segunda onda do feminismo, que teve início na década de 1960.

O primeiro motivo para nosso questionamento surgiu quando, ao procurar pelas mulheres que lutaram contra a ditadura militar no estado, todas que tivemos notícia e se dispuseram a dar depoimento haviam sido da Ação Popular. Outra causa surgiu durante as pesquisas para nosso trabalho de dissertação de mestrado, quando verificamos em estatísticas levantadas por Marcelo Ridenti, historiador e professor titular da UNICAMP (Universidade de Campinas), a partir dos processos arquivados pelo projeto Brasil Nunca Mais, que o percentual de mulheres vinculadas à organização era consideravelmente alto, em relação aos demais partidos de esquerda que atuaram no período. E, por fim, e aí se encontra o motivo principal: entre um total de doze entrevistados em nossas pesquisas, cinco eram mulheres, ou seja, representando um percentual de $42 \%$.

Dessa forma, analisar as razões para a grande inserção de mulheres na Ação Popular tornou-se um problema altamente necessário e urgente, já que estas chegaram, em alguns momentos e regiões específicas, a compor quase $50 \%$ da organização. Foram sujeitos políticos de grande importância nesse processo, desempenhando inclusive funções diretivas. Buscamos então preencher uma lacuna presente na historiografia a respeito do tema, já que até o momento ela não possui trabalhos que busquem investigar especificamente os elementos que contribuíram para uma maior participação feminina na AP e o que contribuiu diretamente para a integração desta na política brasileira. Para tal, nos será de grande valia a utilização recorrente das categorias de público e privado. Procuraremos demonstrar os limites definidos historicamente às esferas sexuais e a delimitação de espaços para os gêneros masculino e feminino (MATOS, 2007, p. 285).

Nesse sentido, este trabalho, que segue a linha dos estudos de gênero, tem a intenção de contribuir com novas pesquisas e perspectivas sobre as esquerdas e a política brasileira, buscando, por meio da articulação e inter-relação dos discursos, 


\section{HISTÓRIA}

Dossiê: Ensino de História, História das Mulheres e Desigualdades Sociais no Brasil

promover a descentralização dos sujeitos historicamente constituídos, levantando as experiências e anseios dos agentes silenciados na prática histórica convencional, neste caso as mulheres. No entanto, a temática sobre as mulheres não busca apenas ampliar os limites da disciplina e possibilitar novos campos de pesquisa, mas também dar voz à experiência histórica das mulheres, sempre trabalhando de forma relacional ambos os gêneros (MATOS, 2007, p. 279-280).

Os estudos com abordagem de gênero só são possíveis se nos valermos de uma diversidade de documentos e metodologias, como a História Oral, que vem sendo utilizada intensamente para o bom desempenho das pesquisas. A História Oral, enquanto método, é de extrema relevância nesse tipo de trabalho, pois, ao mesmo tempo em que tenta minimizar o problema das lacunas históricas, ou a escassez das fontes escritas, privilegia a análise de grupos marginalizados e minorias. Nesse sentido, memórias subterrâneas e há muito tempo silenciadas, como das mulheres, são resgatadas e valorizadas, em contraposição à memória oficial, que geralmente é masculina (POLLAK, 1984, p. 4).

É preciso levar em consideração a especificidade dos relatos apresentados pela autora, principalmente em relação aos ex-militantes da Ação Popular em Goiás, pois tais memórias são permeadas por experiências traumáticas, relacionadas à clandestinidade, à perseguição, aos sequestros, à tortura e/ou à prisão, situação a qual, em muitos casos, preferiu-se calar e tentar esquecer (POLLAK, 1989, p. 7). Existem nas lembranças dessas pessoas zonas de sombra, silêncios e não-ditos. As fronteiras entre informações não reveladas e o esquecimento, não são estáticas e estão em constante deslocamento. Esses silêncios igualmente são condicionados pela falta de escuta, o medo de punição pelo que se diz, ou de se expor em malentendidos (POLLAK, 1989, p. 8). Segundo o sociólogo austríaco Michael Pollak, as condições da atualidade fazem toda a diferença para que esses relatos venham à tona, demonstrando a importância em se dar visibilidade a esses relatos:

Distinguir entre conjunturas favoráveis ou desfavoráveis às memórias marginalizadas é de saída reconhecer a que ponto o presente colore o passado. Conforme as circunstâncias, ocorre a emergência de certas lembranças, a ênfase é dada a um ou outro aspecto (POLLAK, 1989, p. 8). 


\section{HISTÓRIA}

Dossiê: Ensino de História, História das Mulheres e Desigualdades Sociais no Brasil

Segundo Jacques Le Goff (1990. p.472), a memória coletiva pode ser concebida como o que fica do passado no vivido dos grupos ou o que os grupos fazem do passado. Diante disso, é importante ressaltar que essa memória coletiva, no que tange tanto a experiência dos estudantes da Ação Católica brasileira, quanto dos exmilitantes da Ação Popular, também é composta por pontos de vista particulares e individuais, inclusive no que se refere à participação das mulheres. Segundo o sociólogo francês Maurice Halbwachs (2006, p. 71-72), além de haver uma diferença entre memória coletiva e individual, existe também interação e mútua interpenetração de ambas em algumas ocasiões, demonstrando que a memória individual pode reforçar algumas lembranças, ou mesmo preencher as lacunas, porém sempre se apoiando na memória coletiva.

Em nosso trabalho, que visa levantar e analisar os elementos ideológicos e simbólicos que teriam propiciado uma maior participação das mulheres na Ação Popular, desde as raízes cristãs do movimento, recorreremos a vários tipos de documentos, que abarcam tanto fontes escritas - boletins, encíclicas papais, etc. quanto fontes orais, provenientes de entrevistas feitas com ex-militantes (homens e mulheres) da AP, mas principalmente dos movimentos de estudantes da Ação Católica brasileira, como veremos mais adiante.

Nosso tema é relativamente novo e, portanto, de pouca bibliografia. Por isso, nos utilizaremos basicamente de duas obras para construir uma análise especificamente de gênero em nosso texto: Masculino e feminino no imaginário católico: da Ação Católica à Teologia da Libertação, de Zaíra Ary, principalmente; e A mulher na sociedade de classes, de Heleieth Saffioti. Dessa forma, buscaremos sempre fazer uma inter-relação entre fontes, bibliografia específica e geral a fim de responder à principal questão deste trabalho: afinal, por que a Ação Popular arregimentou mais mulheres que as demais organizações da Nova Esquerda brasileira?

A Ação Popular como movimento e partido político da nova esquerda 


\section{HISTÓRIA}

Dossiê: Ensino de História, História das Mulheres e Desigualdades Sociais no Brasil

A Ação Popular foi uma organização da chamada nova esquerda, que existiu entre meados de 1962 até 1974, no Brasil. Ela pode ser enquadrada em tal definição, pois pertenceu às organizações e partidos clandestinos de esquerda que fizeram oposição aos Partidos Comunistas de tradição soviética, no caso do Brasil o Partido Comunista Brasileiro, propondo-se a dirigir, de diferentes formas, a classe trabalhadora na construção do socialismo. Diante disso, a expressão Nova significa tão-somente que se tratava de tendências políticas diversas, o que não implica considerar as anteriores como velhas ou obsoletas (REIS FILHO, 2007, p. 16).

Nesse sentido, a década de 60 foi marcada pelo surgimento de inúmeras organizações, que, em uma conjuntura de intensa agitação política e popular, foram claramente influenciadas por uma série de eventos nacionais e internacionais, tanto no ramo da política, como no da música e do comportamento. A luta pelas Reformas de Base, de João Goulart, a Revolução Cubana, a Revolução Chinesa e o movimento de Contracultura ${ }^{2}$, entre tantos outros, são exemplos de acontecimentos que influenciaram fortemente a juventude brasileira naqueles anos (SILVA, 2010, p. 5). Ao mesmo tempo, é imprescindível que citemos a ocorrência da segunda onda feminista, iniciada na Europa e nos Estados Unidos, em que as mulheres participantes, em sua maioria, tinham algum vínculo com movimentos nascidos naquela década, inclusive as organizações de esquerda (ABREU, 2010, p. 27). Falaremos melhor sobre este fenômeno mais adiante.

A AP surgiu em 1962, em Belo Horizonte, mas foi formalmente fundada em fevereiro de 1963, em Salvador, em sua terceira reunião e I Congresso da AP (ARNS, 1986, p. 100; RIDENTI, 2007, p. 226, 231). Sua criação deu-se, em particular, no interior da JUC (Juventude Universitária Católica), porém também tiveram participação nesse processo outros grupos de jovens da Ação Católica Brasileira, como a JEC (Juventude Estudantil Católica) e a JOC (Juventude Operária Católica), além de grupos protestantes de movimentos renovadores inspirados pelas ideias e

\footnotetext{
2 Contracultura é um termo utilizado para abranger diversos movimentos civis e políticos do Ocidente, principalmente nas décadas de 60 e 70 . Foram movimentos ocasionados por grande descontentamento, principalmente das camadas médias, frente à realidade histórica do período e por crises existencialistas que exigiam revisão das relações sociais. Dentre esses grupos descaram-se os movimentos hippie, estudantil, feminista e negro (CRUZ, 2009).
} 


\section{HISTÓRIA}

Dossiê: Ensino de História, História das Mulheres e Desigualdades Sociais no Brasil

experiências do pastor e missionário presbiteriano Richard Shaull. Seu quadro inicial de militantes não veio apenas das fontes cristãs. Estudantes não-religiosos que eram igualmente contra o PCB e as outras novas organizações da esquerda também compuseram este primeiro quadro. Todavia, é inegável que as lideranças da JUC desempenharam papel predominante e mais significativo no processo de criação da AP, a partir de seu engajamento no movimento estudantil (ARNS, 1986, p. 100, RIDENTI, 2007, p. 227).

Ao verificar a composição inicial da organização, podemos perceber, principalmente nos seus primeiros anos, até mais ou menos 1965, sua vinculação com o movimento teológico latino-americano denominado cristianismo da libertação. Tal corrente ideológica surgiu no Brasil no início dos anos 60 entre setores do clero e do laicato vinculados à ACB, a partir de uma variação da Doutrina Social da Igreja. Esta, de acordo com Flávio Sofiati, surgira como resultado de transformações que ocorreram simultaneamente na Igreja Católica e na sociedade, por exemplo, a eleição do Papa João XXIII, em 1958, e a vitória da Revolução Cubana, em 1959. A JUC teve um papel fundamental nesse processo, após uma significativa mudança de perspectivas em decorrência do envolvimento progressivo de seus militantes junto à UNE (União Nacional dos Estudantes), que naquele momento tomava posições esquerdistas e socialistas. O cristianismo da libertação apregoava novas formas de prática religiosa e uma reflexão espiritual diretamente ligada às questões sociais, integrando, em maior ou menor grau, alguns elementos do marxismo, exceto no que se referia à crítica da religião (LÖWY, 2007, p. 411-413; SILVA, 2016; SOFIATI, 2012, p. 33-34). Deste modo, a inovação dessa nova cultura religiosa é caracterizada pelos seguintes aspectos:

a radicalização da crítica ao capitalismo; combinação da crítica moral e científica - sobretudo marxista - da exploração; substituição da noção de caridade pela de justiça social; [...] proposição da construção de uma nova economia socializada (SOFIATI, 2012, p. 33).

Assim como aconteceu com os demais grupos que combateram a Ditadura Militar no Brasil após 1964, as bases sociais da Ação Popular encontravam-se principalmente nas camadas médias intelectualizadas e jovens. De acordo com os quadros estatísticos montados por Marcelo Ridenti, a partir dos processos judiciais 


\section{HISTÓRIA}

Dossiê: Ensino de História, História das Mulheres e Desigualdades Sociais no Brasil disponibilizados pelo Projeto Brasil Nunca Mais (BNM), entre os processados pela Justiça Militar por vinculação com a AP, 53\% tinham no máximo 25 anos e 41,3\% encontravam-se na faixa entre 26 e 35, quadro formado, em sua maioria, por estudantes e profissionais liberais. Esses dados reiteram o fato de que a militância da AP advinha predominantemente das camadas médias intelectualizadas e que sua maior linha de atuação política sempre esteve no movimento estudantil. Porém, isso não significa que ela deixasse de atuar em outras frentes, como o movimento operário e, principalmente, o camponês, junto ao qual a organização desenvolvia trabalhos políticos em vários estados (RIDENTI, 2007, p. 256-257).

A Ação Popular, como organização da nova esquerda brasileira, possuía diversos elementos em comum com as demais, mesmo que o seu surgimento tenha se dado a partir de uma matriz ideológica distinta, própria do catolicismo. No entanto, alguns processos se desenvolveram de forma muito distinta na AP, inclusive no que se refere à inclusão de gênero. De acordo ainda com as estatísticas organizadas por Ridenti, $73 \%$ dos processados da AP eram homens e $27 \%$ mulheres, o que demonstra uma participação feminina acima da média em relação às demais organizações, que não chegava a $20 \%$. Este fato propiciou uma gama de trabalhos sobre a experiência das mulheres da Ação Popular, tais como: o livro Moças de Minas, de Luiz Manfredini (1989); a dissertação Memória(s) militante(s): narrativas autobiográficas e imagens de resistência em Derlei Catarina De Luca (2015); a monografia As mulheres que lutaram contra a Ditadura Militar em Goiás: o caso da Ação Popular, de minha autoria (2011); entre tantos outros. Na mais completa obra sobre a Ação Popular, de autoria de Otto Filgueiras (2014), intitulada Revolucionários sem rosto: uma história da Ação Popular, há um tópico inteiramente dedicado à experiência de mulheres na organização, no qual são citadas: Dodora ${ }^{3}$; Annete Scotti ${ }^{4}$; Elizabeth Hermano; Alda Maria Borges ${ }^{5}$; Maria José Jaime ${ }^{6}$, entre outras (FILGUEIRAS, 2014, p. 148-152).

\footnotetext{
3 Dodora, da regional de Belo Horizonte, fora integrante da JEC (Juventude Estudantil Católica) e da JUC (Juventude Universitária Católica), tendo grande importância na preparação de um dos primeiros encontros para a criação da AP como movimento político.

${ }^{4}$ Annete frequentara a JUC em Belo Horizonte e depois, na AP, já em Goiás, desenvolvera importante atividade nos Clubes de Mães nas periferias da cidade de Goiânia e no interior do estado.

${ }^{5}$ Alda Maria Borges participara da JUC em Goiânia e na AP fizera parte da Direção Seccional.

${ }^{6}$ Maria José Jaime, a Bizeh, participante da JUC, em Goiânia, também recebera funções de direção tanto na regional que englobava Goiás e Minas Gerais, quanto no âmbito nacional, durante a clandestinidade.
} 


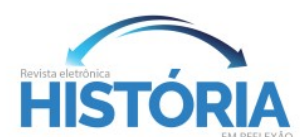

Dossiê: Ensino de História, História das Mulheres e Desigualdades Sociais no Brasil

A respeito da participação das mulheres da Ação Popular, em Goiás Jackson Luiz P. Machado, ex-integrante da organização em Goiânia entre os anos de 1967 e 1969, revelou em entrevista concedida à autora que, na verdade, entrou na AP por intermédio de uma mulher:

Foi nessa época que eu fiquei conhecendo várias pessoas que eram universitárias em sua grande maioria. Foi esse pessoal que me procurou. Elizabeth Hermano era uma baixinha agitada e era ela, eu creio, como universitária, é que comandava entre as meninas, ela seria uma das chefes da AP, eu imagino. Como tinha muita mulher, sabe, obviamente eram elas as chefes, que eram as lideranças, obviamente (MACHADO, 2015).

Uma das militantes goianas que teve papel de direção até mais ou menos 1967, Alda Maria Borges Cunha, em entrevista concedida à autora, afirmou que a mulher desempenhou um papel de expressividade na Ação Popular não apenas quantitativamente, mas qualitativamente, dando como exemplo o caso de Goiás:

E com relação à condição da mulher nesse processo todo eu destacaria uma coisa: que há uma base da AP muito forte, aqui entre nós, da presença feminina e de uma presença feminina marcada pelas discussões teóricas de peso. Eu destacaria nessa condição da mulher a Maria José Jaime, a Bizeh, a Aparecida Siqueira, Elizabeth Hermano, Sebastiana Bitencourt, que era a nossa grande teórica, era quem traduzia para nós coisas de Althusser, coisas do Debrey, coisas de Bernanos, coisas que vinham em francês. A Sebastiana era capaz de traduzir e sentar numa roda de discussão e de debate. [...] Então havia um expressivo suporte feminino compondo a base da AP aqui. Não só pelo número de participantes, mas também pela própria densidade teórica, que essas pessoas conseguiam dar. Eram pessoas de leitura, capazes de sustentar debates, de redigir, pessoas capazes de desempenhar esse suporte teórico fazendo com que a gente não caísse num ativismo não-refletido, desgarrado (CUNHA, 2015).

Como citamos anteriormente, a década de 1960 também foi o cenário de formação da segunda onda do feminismo. Nesse contexto de efervescência política e cultural, o movimento feminista incorporou e radicalizou ideias que já estavam em voga, como a politização do privado; a crítica à democracia representativa e ao modelo ortodoxo de revolução que era defendido pelos partidos comunistas; como muitas outras (ABREU, 2010, p. 27). 


\section{HISTÓRIA}

Dossiê: Ensino de História, História das Mulheres e Desigualdades Sociais no Brasil

Simone de Beauvoir foi a principal autora dessa onda do feminismo, sendo $\mathrm{O}$ segundo sexo lido por uma geração de feministas por todo o mundo. Segundo Maira Luisa Abreu (2010, p. 34), a icônica frase de sua obra, Não se nasce mulher, torna-se mulher, resume sua principal contribuição ao movimento. Com isso, Beauvoir afirma ser o feminino uma construção social, abrindo novos horizontes para o feminismo. Vinte anos após a publicação da obra, milhares de mulheres viriam a tomar a ideia como bandeira. Essas mulheres, então, se engajaram numa luta coletiva, se referindo como nós, e organizaram um movimento em combate à opressão de gênero (ABREU, 2010, 34).

Sabemos que Simone de Beauvoir não se afirmava feminista em $O$ segundo sexo. Segundo ela, para que a opressão da mulher fosse superada era necessária uma profunda transformação da sociedade, provocada por uma revolução socialista, ideia compartilhada pela tradição dos partidos comunistas. No entanto, o feminismo que surgiu ao final da década de 1960 criticava fortemente essa perspectiva. O marxismo estava no centro do debate nos primeiros anos do feminismo, e foi por meio dessa teoria que muitas mulheres buscaram elementos para promover uma explicação social para a subornação feminina. Segundo Abreu (2010, 34), em citação a Rubin, é impossível entender de forma plena a segunda onda do feminismo sem compreender a relação direta, ainda que conflituosa, com a política da nova esquerda e com o pensamento marxista.

A Ação Popular, assim como as outras esquerdas que atuaram no país, certamente recebeu influência direta da segunda onda do feminismo, porém isso se deu mais ao final da década de 1960 e início de 1970. Segundo os depoimentos apresentados anteriormente, desde a sua criação a AP teve um diferencial em reação às demais, o que certamente contribuiu para o aumento progressivo de mulheres na UNE (União Nacional dos Estudantes), a partir dos anos 60, e concomitantemente para a maior participação das mesmas na política brasileira. Afinal, a organização detinha a hegemonia da entidade estudantil até mais ou menos o final da década. Com a sua unificação junto ao PCdoB (Partido Comunista do Brasil) em 1974, este passou a ser predominante naquela instituição, sendo um dos partidos que possuem proporcionalmente elevado número de mulheres em seus quadros. Atualmente, entre os 8 representantes do PCdoB na Câmara dos Deputados, 4 são mulheres. O partido 


\section{HISTÓRIA}

Dossiê: Ensino de História, História das Mulheres e Desigualdades Sociais no Brasil

igualmente, há alguns anos, vem desenvolvendo iniciativas diretamente voltadas para a condição feminina, como a Secretaria Nacional da Mulher - PCdoB.

Como pudemos verificar até o momento, a composição social da Ação Popular não era diferente da das demais organizações da nova esquerda brasileira, pois seus militantes advinham principalmente das classes médias urbanas intelectualizadas. Em Goiás, por exemplo, podemos dizer que, em mais ou menos 12 anos de trajetória, a AP passou por fases e houve pequenas alterações em relação à sua composição social. Entre os anos de 1965 e 1967, os dirigentes procuraram desenvolver trabalhos paralelos em cidades do interior, que já tinham uma tradição de luta. O município de Itauçu, por exemplo, foi uma das regiões de atuação do partido, que, por meio de diferentes frentes de atuação política, como o MEB (Movimento de Educação de Base), também vinculado à Igreja Católica, chegou arregimentar um número considerável de lavradores e camponeses, como Oscavú José Coelho e seu irmão Parcival Moreira Coelho (COELHO, 2004). Outra região que chamou a atenção, em 1968, dessa vez de uma dissidência da AP, o PRT (Partido Revolucionário dos Trabalhadores), foi a de Trombas e Formoso, também devido ao histórico de lutas, como a vitoriosa resistência dos posseiros e a fundação dos sindicatos rurais, que contaram com o apoio do PCB (Partido Comunista Brasileiro), na década de 1950 e início de 1960 (O POPULAR, 2014).

Todavia, em Goiás, a composição social da Ação Popular, durante toda a sua trajetória, foi composta primordialmente por estudantes, sendo universitários ou secundaristas. Igualmente ao que se percebeu em Belo Horizonte, onde foi fundada a organização, havia uma predominância de estudantes de Ação Católica (JUC e JEC), sendo Uassy Gomes da Silva, um jucista, o primeiro coordenador da AP no estado (SILVA, 2015). Segundo Gilberto Franco Teixeira, que fora dirigente da AP em Goiás, a reunião que oficializou a fundação da organização no estado contou com a presença de pessoas de diferentes seguimentos profissionais e religiosos, porém fora coordenada por militantes da JUC:

Eu me lembro bem da reunião, que estava sendo coordenada pelo Uassy, era o pessoal universitário, e eu estava saindo da JEC para entrar na universidade, estava nesse período de transição, foi em 63 [...]. E aí foi isso: tinha secundarista, universitário, operário, tinha gente de toda matiz de atividade, de religiosidade (TEIXEIRA, 2015). 


\section{HISTÓRIA}

Dossiê: Ensino de História, História das Mulheres e Desigualdades Sociais no Brasil

Levando em consideração que a base social dos militantes da AP era semelhante à das demais organizações e partidos, que lutaram contra a Ditadura Militar instaurada em 1964, qual teria sido o diferencial desta organização para proporcionar uma maior inserção das mulheres no conjunto de sua militância? A resposta não poderia estar exatamente no elemento que distingue a Ação Popular das demais, que é a sua origem nos movimentos de jovens da Ação Católica Brasileira? É o que analisaremos nos próximos tópicos.

Marianismo: poder ou contrapoder das mulheres?

$\mathrm{Na}$ bibliografia específica que aborda os modelos simbólicos que historicamente têm influenciado na socialização e na formação das identidades feminina e masculina, o marianismo, ideologia estipuladora de um estereótipo derivado do culto católico à Virgem Maria, aparece no Brasil e na América Latina como um todo, de acordo com Zaíra Ary em citação a Evelyn Stevens, como a outra face do machismo (STEVENS, 1977 apud ARY, 2000, p. 72). Para a autora, o marianismo como edifício secular de crenças e de práticas relativas à posição da mulher na sociedade, um suporte ideológico que muitas vezes mimetizara o machismo, referese ao:

culto à superioridade espiritual feminina que considera as mulheres semidivinas, moralmente superiores e espiritualmente mais fortes do que os homens. Esta força espiritual engendra a abnegação, quer dizer, uma capacidade infinita de humildade e de sacrifício (STEVENS, 1977, p. 123).

O marianismo ganhou força no ideário latino-americano de forma a influenciar, inclusive, os discursos intelectuais não-cristãos, como o dos positivistas brasileiros dos séculos XIX e XX. Para estes, a mulher era a base da família, que por sua vez era tida como a base fundamental da sociedade. A mulher representaria o núcleo moral da sociedade, manifestando-se, sobretudo, através dos sentimentos, ao contrário do homem. Portanto, a feminilidade deveria ser adorada e resguardada de 


\section{HISTÓRIA}

Dossiê: Ensino de História, História das Mulheres e Desigualdades Sociais no Brasil

um mundo perverso, ou seja, relegando à mulher apenas os espaços privados da sociedade: os redutos familiares (ARY, 2000, p. 73).

Através deste pensamento, a Igreja Católica difundira um protótipo ideal de mulher - a Virgem Maria -, merecedora de exaltação por ter se despojado de sua sexualidade, sendo modesta, silenciosa e humilde, tornando-se assim a imagem da mãe ideal. Alguns teólogos chegaram a sugerir que Maria, de tão perfeita, teria se tornado um homem. Segundo a teóloga feminista, verificando a recorrência desse tema na literatura cristã primitiva, a expressão metafórica tornar-se homem significa a evolução de um estágio inferior a um estágio superior de perfeição moral e espiritual (ARY, 2000, p. 74; VOGT, 1985, p. 78-90 apud ARY, 2000, p. 74).

No entanto, a mulher apenas se aproximaria do valor social e simbólico que o homem tinha para a Igreja se, porventura, se abstivesse de sua sexualidade, tal qual Maria. Esse modelo pareceu inculcar nas mulheres-esposas-mães, por certo tempo, uma espécie de culpa devido à impossibilidade de realizar a maternidade virginal, assexuada, e também pela impossibilidade de salvar a sociedade a partir da família. Porém, até os dias atuais, as missões salvadoras, culturalmente e religiosamente atribuídas, parecem permanecer como única oportunidade de reconhecimento e de valorização das mulheres no catolicismo. De acordo com Zaíra Ary, a partir de tal análise pode-se perceber que, em todas as modalidades teológicas, com suas diversas perspectivas históricas, culturais e ideológicas, as mulheres são reificadas, ou seja, são consideradas como sexo-objeto em seus diversos papéis, sendo sedutoras, servas ou salvadoras do sexo-sujeito, representado pelos homens (ARY, 2000, p. 77-79).

A atribuição desse papel às mulheres fica bastante evidenciada em algumas bulas papais, como o Discurso à juventude feminina da Ação Católica, de 24 de abril de 1943, proclamado pelo Papa Pio XII. Como afirma Heleieth Saffioti, Pio XII destina a mulher à maternidade, de forma que todas as outras funções que ela viesse a desempenhar na sociedade eram secundárias e mantinham o caráter complementar às atividades masculinas. Segundo Saffioti (2013, p. 151), a possibilidade de realização para a mulher era tornar-se mãe e esposa; somente assim, ela poderia salvar a sua alma do terrível pecado que assolava seu destino. Na seguinte 


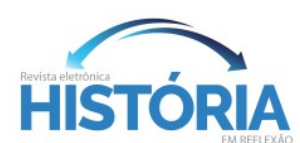

Dossiê: Ensino de História, História das Mulheres e Desigualdades Sociais no Brasil

declaração do Papa Pio XII fica evidente a afirmação desse papel, dado como natural às mulheres:

\begin{abstract}
Em um como em outro estado (civil) o dever da mulher aparece nitidamente traçado pelos lineamentos, pelas atitudes, pelas faculdades peculiares ao seu sexo. Colabora com o homem, mas no modo que lhe é próprio, segundo sua natural tendência. Ora, o ofício da mulher, sua maneira, sua inclinação inata, é a maternidade. Toda mulher é destinada para ser mãe; mãe no sentido físico da palavra, ou em um significado mais espiritual e elevado, mas não menos real. $A$ este fim o Criador ordenou todo o ser próprio da mulher, seu organismo, mas também seu espírito e sobremodo sua especial sensibilidade. De modo que a mulher, verdadeiramente tal, não pode de outro modo ver nem compreender a fundo todos os problemas da vida humana, senão com relação à família. Por isto o sentido agudo de sua dignidade a coloca em apreensão cada vez que a ordem social ou política ameaça prejudicar sua missão materna, em favor da família (CHINIGO, 1960, p. 111).
\end{abstract}

Dessa forma, Pio XII estabelecia uma separação entre a família e a sociedade na vida da mulher. Esta deveria deter-se ao meio familiar, ao espaço privado, mantendo-se mais ou menos alheia da amplitude social, a qual poderia ser acompanhada apenas da perspectiva da família. Neste discurso, é reiterada a visão de que a mulher seria apenas um apêndice do grupo familial, ao qual estava confinada (SAFFIOTI, 2013, p. 151).

É importante deixar claro, porém, que a ideologia marianista, que estipula a imagem de um modelo ideal do feminino, foi interiorizada de forma mais ou menos acentuada em determinadas mulheres, de acordo com os contextos individuais e socioculturais, como a classe social, momento histórico, inclusive o grau de influência que a religião católica exerceu sobre a formação de sua consciência individual. Um exemplo disso foi a perda de influência do marianismo no início dos anos 60 , momento em que a própria Igreja verificara os problemas que o culto a Maria trazia para o movimento ecumênico, liderado pelo Papa João XXIII através do Concílio Vaticano II, em 1961. Por outro lado, outro fator que seria responsável pelo enfraquecimento de tal modelo, durante aqueles anos, foi o aumento progressivo do nível de instrução da mulher brasileira de classe média, o que poderá ser verificado com clareza nas integrantes da JUC (Juventude Universidade Católica), como veremos mais adiante (ARY, 2000, p. 81; LÖWY, 2007, p. 414). 


\section{HISTÓRIA}

Dossiê: Ensino de História, História das Mulheres e Desigualdades Sociais no Brasil

\section{A Ação Católica Brasileira}

A Ação Católica foi lançada no Brasil em 1923 por Dom Sebastião Leme, arcebispo do Rio de Janeiro, com o intuito de renovar a Igreja e minimizar a perda de fieis, partindo das elites. Daí em diante, ela se estende para capitais como Recife, São Paulo, Belo Horizonte e Porto Alegre (SEMERARO, 1994, p. 39).

Durante as primeiras décadas da Ação Católica no Brasil, ela seguiu os movimentos de tendência europeia, mais especificamente o modelo italiano, que definia a unificação de todas as organizações católicas leigas sob uma organização geral, estruturando-se, assim, em quatro ramos fundamentais, separados por gênero, idade e nupcialidade: Homens da Ação Católica (HAC); Liga Feminina de Ação Católica (LFAC); Juventude Católica Brasileira (JCB); Juventude Feminina Católica (JFC) (ARY, 2000, p. 91-92; SOFIATI, 2012, p. 40).

O Papa Pio XI, considerado o patrono da Ação Católica, ressaltava a necessidade destes movimentos, principalmente devido à defasagem dos quadros do clero, mas alertava que deveria haver uma unidade orgânica, fazendo de cada indivíduo um apóstolo de Cristo no ambiente social onde estiver. O leigo deveria ser um representante na hierarquia clerical no seio da sociedade, devendo manter respeito à rígida estrutura à qual se vinculava. No entanto, mesmo que a Ação Católica tenha sido uma tentativa da Igreja de adequar sua doutrina às expectativas sociais daquele momento, a Alta Hierarquia clerical, extremamente centralizadora e autoritária, não permitiria abertura no poder aos leigos, principalmente para os jovens, que geralmente constituíam os grupos de maior questionamento (SAFFIOTI, 2013, p. 141; SOFIATI, 2012, p. 38-39).

A partir da sua oficialização no Brasil, deu-se um desenvolvimento bastante desigual nos seus vários núcleos militantes, com a afirmação cada vez maior da Ação Católica especializada, ou seja, voltada aos seus meios social, operário, estudantil, universitário, independente e agrário. Em certos momentos de sua trajetória, alguns setores especializados da ACB puseram fim à separação por gênero vigente na organização do trabalho apostólico, enquanto outras a mantiveram. A JUC teve a sua 


\section{HISTÓRIA}

Dossiê: Ensino de História, História das Mulheres e Desigualdades Sociais no Brasil

unificação oficializada desde 1950, enquanto a JEC continuou dividida até o seu desaparecimento, em 1967 (ARY, 2000, p. 92).

Além do tom de superioridade e universalidade que era legado pelo padrinho da Ação Católica no Brasil, Dom Sebastião Leme, aos leigos daquele movimento, dizendo-os especiais, exército apostólico a serviço do Cristo Rei e de sua Igreja, junto do Papa, junto dos bispos e seus sacerdotes. Nas próprias cartas do Papa Pio XI aos bispos brasileiros, nos anos de 1935 e 1936, podem-se observar trechos repletos de metáforas militares e a presença de um modelo viril para os leigos, considerados membros necessários como auxiliares da Hierarquia da Igreja na sua missão de evangelização da sociedade, sendo tal modelo direcionado igualmente a ambos os sexos. Um exemplo disso é o ideal de heroísmo, evidente na carta de Pio XI a Dom Leme, em 1936, no II Congresso Eucarístico Nacional, que exaltava esta qualidade requisitada a todos os soldados, sobretudo à causa sobrenatural, como podemos ver:

Urge advertir que, no promover o bem do próximo, devem estar prontos os apóstolos da Ação Católica, ao modo dos primitivos atletas de Cristo, não só a enfrentar toda sorte de trabalhos e perseguições, como a arrostar ainda, se a tanto forem levados, morte gloriosa (DALE, 1985, p. 44-45 apud ARY, 2000, p. 95).

Como já dissemos anteriormente, a ACB inspirara-se, inicialmente, no modelo italiano de Ação Católica e aqueles anos coincidiram com o regime fascista na Itália e a Segunda Guerra Mundial. Muito provavelmente esses processos influenciaram as referências militares presentes naquele movimento laico. O próprio Getúlio Vargas assumia, frente ao regime italiano, uma postura de grande admiração e proximidade. Dessa forma, já em 1937, pode-se verificar que o discurso dos militantes brasileiros assimilara bem as metáforas militares contidas nos textos do Papa. Além da ideia de heroísmo contida nos pronunciamentos dos militantes, também fica clara a exigência imposta a eles de perfeição absoluta, como podemos perceber no tema de uma das sessões destinadas aos homens, jovens e universitários da Primeira Semana Nacional de Ação Católica: A formação moral: o soldado da Ação Católica deve ser exemplar na vida - privada, familiar, profissional, social - sempre e em qualquer posto e em toda a parte (DALE, 1985, p. 53 apud ARY, 2000, p. 95). 


\section{HISTÓRIA}

Dossiê: Ensino de História, História das Mulheres e Desigualdades Sociais no Brasil

Em 1946, na Segunda Semana Nacional da Ação Católica, que acontecera no Rio de Janeiro, tendo depois se transformado no Primeiro Congresso Nacional da Ação Católica, percebe-se, no texto oficial sobre a natureza e os fins da Ação Católica, uma repetição do tema heroísmo indispensável. Nos discursos do evento, as prescrições viris, como o ideal de heroísmo, ficavam subentendidas ou explicitadas nas metáforas, como prova o uso frequente das palavras exército (apostólico), batalha (sagrada), soldados, batalhões, falanges, militar, linha de combate, campo de combate, etc.

Naquele momento, como todos os grupos ainda eram separados por gênero, o Papa e outros líderes evitavam utilizar-se dessa linguagem marcial quando se dirigiam às mulheres, exceto quando, rara e inconscientemente, consideravam-nas como se elas fossem homens, como vimos anteriormente. Essa ambiguidade no discurso da Igreja fica evidente, em se tratando de Ação Católica, quando identificamos tais modelos viris com o que Zaíra Ary chama de cristocentrismo, ou seja, uma atuação centrada no modelo masculino do Cristo, o oposto do feminino expresso no marianismo. Nesse plano ideológico, o masculino sempre seria a categoria de referência da trama social, política e, inclusive, do sagrado, o que é facilmente verificado na propagação do ideal de virilidade como sinônimo de ação (ARY, 2000:97). No entanto, acreditamos que, muito provavelmente, foi a ideologia deste mesmo cristocentrismo, vinculada ao processo de inclusivismo na Igreja Católica, iniciado na década de 60 e impulsionado pelo Concílio Ecumênico Vaticano II, do Papa João XXIII (SCHULTZ, 2013), como veremos mais adiante, que possibilitou, de forma primordial, uma maior inserção das mulheres da juventude católica no meio público e nas atividades políticas.

\section{A Juventude Estudantil Católica Feminina (JECF) no Brasil: marianismo e engajamento}

A primeira manifestação da supremacia masculina na Ação Católica está na maneira de nomear os setores masculino e feminino, sendo o masculino o óbvio, ou 


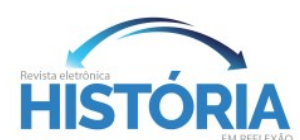

Dossiê: Ensino de História, História das Mulheres e Desigualdades Sociais no Brasil

seja, não havendo a necessidade de ter o gênero especificado, como podemos ver na diferença de nomeação entre JEC e JECF.

$\mathrm{Na}$ JECF, a educação e os papéis sociais a serem atribuídos às estudantes deveriam ser evidenciados, primeiramente, pelas adjuntas religiosas do movimento, como demonstração de subserviência à Hierarquia e de exemplo às militantes. Dessa forma, as adjuntas deveriam submeter-se ao controle maior dos assistentes eclesiásticos, tendo sua função e sua postura femininamente definidas pela doçura e harmonia, em uma cooperação subordinada ao assistente eclesiástico, como podemos perceber no texto oficial do Papa Pio XII destinado ao Primeiro Congresso Nacional da Ação Católica no Brasil, em 1946:

\begin{abstract}
Suavemente e antes de tudo despertar nos adolescentes o espírito de apostolado; depois diligente e assiduamente exortá-los a que se inscrevam nas associações de Ação Católica que, onde esta não existir, hão de os religiosos promover. [...] Competindo essencialmente ao assistente eclesiástico a função de formar consciências dos membros da Ação Católica [...] hão de as religiosas, e especialmente a adjunta técnica, cooperar inteligente e harmoniosamente nesse esforço, a fim de que mais intensamente se deixem embeber do espírito de Cristo, que é o espírito de zelo apostólico (DALE, 1985, p. 71-72).
\end{abstract}

Nos discursos sobre a JECF, inclusive no livro $O$ assistente eclesiástico utilizado pela associação na época, era sempre acentuada a virtude feminina, pautada no marianismo, do serviço, de sempre pensar nos outros, dar-se aos outros, etc., e condenada a busca pelo êxito pessoal, mesmo que esta fosse tolerada e aceita no caso dos jecistas masculinos. Esses discursos direcionados, os quais faziam apelo à tendência mística e servil conferida às mulheres, estavam presentes em todos os boletins da JEC feminina brasileira, de acordo com Zaíra Ary (2000, p. 101-102), ao contrário dos pronunciamentos destinados aos homens, aos quais eram atribuídos os ideais do cristianismo viril, como podemos ver no seguinte trecho:

A adjunta religiosa da JEC deve primeiramente compreender a extensão de suas obrigações como educadora [...]: ser a mãe espiritual de todas as jovens que lhe estão confinadas, formar homens, no verdadeiro sentido da palavra, fazer cristãos vigorosos, convictos (LALEMANT et al, 1954, p. 13 apud ARY, 2000, p. 102). 


\title{
HISTÓRIA
}

\section{Dossiê: Ensino de História, História das Mulheres e Desigualdades Sociais no Brasil}

Com relação à busca pelo êxito pessoal, que pode ser compreendida como a inserção no mercado de trabalho, na política etc., podemos verificar o claro desacordo com o trabalho feminino expressado pelo próprio Papa Pio XII no Discurso à juventude feminina da Ação Católica, de 24 de abril de 1943 (SAFFIOTI, 2013, p. 153):

\begin{abstract}
E para a mulher, voltam-se vários movimentos políticos, para ganhála à sua causa. Alguns sistemas totalitários colocam diante de seus olhos magníficas promessas; igualdade de direitos com os homens, proteção das gestantes e das parturientes, cozinha e outros serviços públicos comuns que libertarão do peso das obrigações domésticas. [...] A igualdade de direitos com o homem, trazendo o abandono da casa onde ela era Rainha, sujeita a mulher ao mesmo peso e tempo de trabalho. Desprestigiou-se a sua verdadeira dignidade e o sólido fundamento de todos seus direitos, quer dizer, o caráter próprio do seu ser feminil e a última coordenação dos dois sexos (CHINIGO, 1960, p. 112).
\end{abstract}

De acordo com Heleieth Saffioti (2013, p. 153,155), a Igreja colocou em vários momentos uma série de dificuldades à integração da mulher na sociedade capitalista, 362 na qual ela já se encontrava em situação periférica. Nesse sentido, a mistificação da consciência feminina, ideia impulsionada pela própria instituição e fortalecida pelo marianismo na América Latina, constituiu fator essencial da manutenção da estrutura social. O próprio Papa, neste pronunciamento, teria reconhecido a possibilidade de integração feminina na sociedade pelas vias utilizadas pelos homens, porém apenas aquelas que se sobressaíssem deveriam levar tal empreitada adiante. Dessa forma, a Hierarquia afirmava a legitimidade do trabalho feminino, supondo que ele partisse de uma dada elite social. Posteriormente, veremos que essa permissão influenciará fortemente na militância feminina da JUC, o que não significa que tenha prevalecido um consenso sobre o tema.

No entanto, a significância da JECF, assim como de outros movimentos de Ação Católica, e o que ela representou na vida das militantes é um fenômeno complexo, indicando claramente a existência de um paradoxo. Se, por um lado, o movimento aplicava diversas limitações, fundamentadas primordialmente no marianismo, a essas mulheres no plano social e afetivo, como a repressão sexualsensual, uma ética de sacrifício desumanizante, a culpabilidade doentia etc., por outro, para a maioria das jecistas e principalmente para aquelas que deram continuidade na 


\section{HISTÓRIA}

Dossiê: Ensino de História, História das Mulheres e Desigualdades Sociais no Brasil

JUC, a participação no movimento foi de enorme importância. São algumas visões positivas sobre tal organismo católico: a mudança de uma prática religiosa para outra completamente diferente da experiência tradicional - uma espiritualidade engajada; passagem da pequena família para uma grande família fraternal representada pelo chamado Corpo Místico de Cristo; experiência de amizade e de liderança em grupo; possibilidade de uma nova perspectiva de vida profissional para as mulheres, indo além do trabalho doméstico (ARY, 2000: 169). Podemos verificar claramente a importância do movimento para essas mulheres no seguinte depoimento concedido por Zaíra Ary (2000, p. 172):

A JECF me abriu, [...] ela me colocou em contato com grupos muito diferentes uns dos outros. Era uma abertura também para fora de casa, pois ela me levou para os acampamentos, para os encontros, para os seminários e até para as missas. [...] Ela me deu uma visão diferente da Igreja. [...] Tudo isso constituiu uma subversão do meu pensamento [...]. A JEC significou isto para mim: uma abertura para o mundo exterior, porque eu estava realmente muito fechada. Esta abertura foi social, porque eu saí da minha casa [...] e foi também uma abertura interior, no sentido da descoberta dos outros, do outro, das pessoas (ANÔNIMA apud ARY, 2000, p. 172).

Nesse sentido, podemos verificar que, mesmo com o desestímulo da Igreja à profissionalização das mulheres, naquele momento a JECF lançou as bases para a inserção dessas militantes no mercado de trabalho e até mesmo na política, a começar pela ampliação de seus horizontes para além do meio familiar e privado, com a promoção de novas sociabilidades e trocas intelectuais. Dessa forma, a JECF foi uma espécie de antessala para uma inserção feminina mais efetiva em outros meios de atuação, a qual atingiria o ápice na JUC, como veremos a seguir.

\section{A JUC: engajamento político e o enfraquecimento do marianismo}

Com o passar dos anos, principalmente no início da década de 1960, momento de forte agitação política no Brasil, os conceitos viris serão progressivamente relacionados à ideia de engajamento político. A JEC permanecera separada até a sua dissolução, sendo discursos advindos da Hierarquia filtrados e proferidos de forma 


\section{HISTÓRIA}

Dossiê: Ensino de História, História das Mulheres e Desigualdades Sociais no Brasil

distinta para cada sexo, mesmo que, eventualmente, fosse impossível um controle total no repasse de informações, devido à inevitável interação entre os militantes, inclusive nos encontros regionais e nacionais. No entanto, tal divisão deixa de existir na JUC desde 1950, de forma que as moças militantes desse movimento receberam uma formação de conotação masculina, pois o meio universitário ainda era constituído, em sua maioria, por homens, o que acreditamos ter influenciado fortemente sua inserção nos meios públicos da sociedade, assim como no movimento político Ação Popular (ARY, 2000, p. 106).

Progressivamente, porém, houve um aumento significativo de mulheres nas universidades brasileiras, de forma que já em 1937 fora convocada a União Universitária Feminina para a criação da UNE (União Nacional dos Estudantes), esta que em 1961 passara a chamar-se Associação Brasileira das Mulheres Universitárias (ROSA, 2015, p. 6-7). A formação e a adequação desses organismos demonstram claramente um aumento significativo de mulheres nos meios universitários, o que surtira a percepção da necessidade de organização e fortalecimento por parte destas estudantes. Dessa forma, rapidamente verificou-se uma maior inserção de mulheres nos quadros da JUC e, igualmente, na UNE, entidade suprema do movimento estudantil, que, a partir de 1960, seria comandada pelos jucistas, com a eleição de Aldo Arantes à sua presidência.

Com relação à orientação ideológica da JUC, de 1951 a 1966, os programas anuais escolhidos pelo Conselho Nacional dos Dirigentes privilegiaram progressivamente, de forma sintética, os seguintes temas: política universitária, cultura, questão social, família, valores, problemas brasileiros, universidade, educação nacional, ideal histórico e revolução brasileira. A partir de 1959, o tema ideal histórico e seus desdobramentos mostraram uma mudança radical nas perspectivas do movimento, de forma que o tema A família e o Estado, abordado em 1955, é destoante se comparado aos temas escolhidos nos anos seguintes. Nesse sentido, ao mesmo tempo que os militantes passavam a se preocupar cada vez mais com o político deixavam de lado os temas relacionados à família.

As transformações ocorridas na JUC claramente têm relações com a conjuntura da sociedade brasileira naquele período, sendo esta guinada acompanhada por uma maior participação da mulher no movimento, o que refletiu diretamente em um dos 


\section{HISTÓRIA}

Dossiê: Ensino de História, História das Mulheres e Desigualdades Sociais no Brasil

temas abordados no seu Congresso dos Dez Anos, em 1960, intitulado A mulher na universidade (ARY, 2000, p. 188-191). Segundo Zaíra Ary (2000, p. 213), tal tema fora muito pouco explorado no evento e, de certa forma, marginalizado, diminuindo sua significância. Porém, acreditamos que somente o fato de este ter sido um dos temas escolhidos para o simpósio já demonstra um aumento da importância feminina no movimento, o que se repetiria na Ação Popular.

O Congresso Nacional de Comemoração aos 10 anos de JUC, ocorrido no Rio de Janeiro, segundo informação de Alda Maria Borges Cunha (2015) e as assinaturas contidas na ficha de inscrição de Maria José Jaime, contou com vários integrantes goianos da JUC, inclusive com participação em peso das mulheres. De acordo com Otto Filgueiras, Goiânia não era apenas um reduto importante da JUC e, concomitantemente, da Ação Popular, mas também uma sede importante na atuação das mulheres, quadro que se repetiu em várias outras capitais do país (FILGUEIRAS, 2014, p. 151).

Tais dados nos levam questionar as possíveis razões que fizeram com que as mulheres tivessem essa inserção, quantitativa e qualitativamente, na JUC, movimento misto, porém ainda de predomínio masculino. Acreditamos que uma categoria central de explicação, na qual já viemos trabalhando, está primordialmente no marianismo, porém, desta vez, no enfraquecimento deste e no fortalecimento do cristocentrismo. Maria, ao contrário da JECF, teve seu nome e figura relativamente esquecidos na JUC, pois o movimento fora desde sempre muito centrado na ideia do Cristo; afinal, por algum tempo a sua grande maioria de militantes era composta por homens. A mariologia, como culto especial feito a Maria, não atraía muito os jucistas, de forma que foi perdendo progressivamente a sua importância na espiritualidade dos militantes e na prática religiosa do movimento. Cristo era o Rei e modelo prioritário (masculino) a ser seguido por ambos os sexos (ARY, 2000: 193, 211). Podemos verificar facilmente esse distanciamento no depoimento de uma ex-militante da JUC: Nossa Senhora era tão inimitável, ela é tão especial, virgem, ela era bela para ser admirada. Até hoje, eu me encho de fotos de Nossa Senhora, mas eu não podia seguir o seu caminho. Ela era como um anjo, o que não era a minha pretensão (ANÔNIMA apud ARY, 2000, p. 211-212). Outro depoimento causa-nos também estranhamento ao 


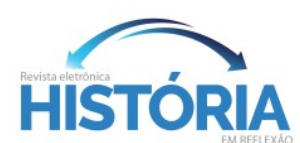

Dossiê: Ensino de História, História das Mulheres e Desigualdades Sociais no Brasil

percebermos que tal desmistificação da figura de Maria partiu, algumas vezes, dos próprios eclesiásticos:

A importância maior era dada ao Cristo; Maria foi uma pessoa muito desmistificada na época. Eu me lembro quando um assistente eclesial da JUC afirmou, em praça pública, que não acreditava na virgindade de Maria; me parece que ele foi punido, sem poder pregar, e que a JUC inteira se colocou do lado dele (ANÔNIMA apud Ary, 2000, 212).

Através deste último depoimento, podemos perceber que, naqueles anos, o enfraquecimento do culto a Maria não foi causado apenas pelos jucistas, mas igualmente por uma mudança no discurso da Hierarquia da Igreja. Como já vimos anteriormente, com o Concílio Vaticano II, de caráter progressista, a Igreja Católica dava início a um diálogo ecumênico junto às demais religiões cristãs, abandonando uma perspectiva exclusivista e lançando-se no inclusivismo. Privilegiou-se, então, o cristocentrismo ante o marianismo, o que teve reflexos diretos entre os fiéis. No entanto, o inclusivismo promovido naqueles anos não significara, de nenhuma forma, uma postura igualitária do catolicismo perante as demais religiões, mas somente uma flexibilização paternalista bem representada no dizer: As outras religiões e igrejas são estágios inferiores da minha (SCHULTZ, 2013, 98, 99).

Dessa forma, será que tal inclusivismo ecumênico não teria contribuído, mesmo que de forma igualmente paternalista e não-igualitária, para uma maior inclusão das mulheres na JUC e, posteriormente, no movimento estritamente político chamado Ação Popular?

\section{Considerações finais}

Procuramos em nosso texto averiguar as possíveis razões para uma maior participação de mulheres nos quadros da Ação Popular, em relação às demais organizações da nova esquerda brasileira. Aquela geração de militantes de esquerda, composta, em sua grande maioria, por intelectuais e estudantes das classes médias, acompanhou as mesmas transformações políticas e sociais no Brasil e no mundo, inclusive a maior inserção da mulher nas universidades e os movimentos feministas. 


\section{HISTÓRIA}

Dossiê: Ensino de História, História das Mulheres e Desigualdades Sociais no Brasil

Dessa forma, qual teria sido o diferencial da Ação Popular? A explicação estaria em suas raízes enquanto movimento de jovens de Ação Católica?

Como pudemos ver até o momento, responder a esta questão não é um objetivo simples, principalmente porque se trata de um processo que congrega diversos fatores. Primeiramente, o aumento progressivo do nível de escolaridade da mulher brasileira ampliara seus horizontes (ROSA, 2015), de forma que, enquanto elevava a titulação, distanciava-se dos papéis exclusivos de mãe e esposa, historicamente a ela atribuídos. Por outro lado, os movimentos de Ação Católica proporcionaram a essas mulheres, desde a década de 30, um outro nível de sociabilidade, organizada e engajada, que as retirava do meio privado, da restrição do ambiente familial, e as colocava em uma espécie de antessala do meio público, com as reuniões semanais, os encontros regionais e nacionais. Dessa forma, mesmo na JEC, organismo no qual a ideologia do marianismo ainda era muito forte e prevalecia a divisão por gênero, essas jovens começaram a experimentar certo nível de autonomia, tanto com relação à religião quanto à sua condição de mulher, que até então a Igreja Católica não proporcionava, na intenção de manter e preservar a unidade familiar, que representava a sua base de sustentação.

Todavia, verificamos que a chave da expressiva participação da mulher na Ação Popular encontra-se na JUC, reduto de universitários católicos que desde 1950 rompera com a divisão de militantes por gênero. Dessa forma, os mesmos discursos de caráter primordialmente masculino foram dirigidos a homens e mulheres, sem distinção, sendo estas consideradas pelo movimento como se fossem homens. Assim, o lema jucista ver, julgar e agir, herança dos conceitos viris disseminados no início da Ação Católica no Brasil, foi também aplicado às universitárias. Nesse sentido, o lema, que inicialmente se referia a um modelo de engajamento apostólico, rapidamente se transformou em índice de engajamento político, devendo este ser aplicado a todos os militantes, inclusive às mulheres. Logo, a autonomia vivenciada por aqueles jovens universitários nas reuniões semanais e encontros da JUC ganharia contornos mais amplos, de inserção direta no movimento estudantil através da UNE, sua entidade suprema, na qual as jucistas, inclusive, passaram a desempenhar diversas funções.

Acreditamos, no entanto, que a maior contribuição da JUC para suas militantes, o que contribuiu de forma decisiva para a sua inserção no meio político, foi o 


\section{HISTÓRIA}

Dossiê: Ensino de História, História das Mulheres e Desigualdades Sociais no Brasil enfraquecimento do marianismo, como estereótipo de mulher, fundamentado no modelo da Virgem Maria, a ser seguido. Dessa forma, e porque a maior parte da JUC ainda era composta por homens, os ideais femininos calcados na mística de superioridade espiritual, que determinava a subserviência e a exclusividade de dedicação ao lar e à família, foram deixados de lado, e substituídos pelos ideais trazidos pelo cristocentrismo, modelo masculino que inclusive influenciou na perspectiva política tomada pelo movimento, o cristianismo da libertação, como já dito anteriormente.

De acordo com nossa análise, esses foram os principais fatores que contribuíram para uma maior participação feminina na Ação Popular, esta que, por sua vez, teria também contribuído diretamente para a inserção feminina no meio político, por exemplo na UNE e no PCdoB, já que alguns dirigentes deste partido, como Euler Ivo (2015), Secretário de Formação em Goiás, dizem ter sido a unificação junto à AP o que de fato deu um corpo militante sólido para a legenda.

Hoje a mulher possui uma boa representatividade no PCdoB, com nomes de peso como Manuela D'ávila, ex-deputada federal, estadual, candidata à vicepresidência em 2018 e criadora do Instituto E Se Fosse Você, que tem como bandeira o combate ao discurso de ódio na internet e às fake news ; Luciana Santos, presidente nacional do partido; as deputadas federais Alice Portugal, Jandira Feghali, Perpétua Almeida, Professora Marcivania; entre muitas outras deputadas estaduais e vereadoras. No entanto, sabemos que muito ainda precisa ser feito para que haja uma igualdade de gênero efetiva na política brasileira, principalmente em relação à conjuntura atual, em que temos percebido uma guinada conservadora em diversos setores da sociedade. E, para tal, por que não começar explorando as raízes desse processo de inserção? Foi o que buscamos fazer neste trabalho.

\section{Referências}

ABREU, Maira Luisa Gonçalves de. Feminismo no Exílio: o Círculo de Mulheres Brasileiras em Paris e o Grupo Latino-Americano de Mulheres em Paris. Dissertação de Mestrado em Sociologia - Instituto de Filosofia e Ciências Humanas, Universidade Estadual de Campinas. Campinas, p. 265, 2010. 


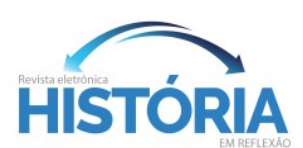

Dossiê: Ensino de História, História das Mulheres e Desigualdades Sociais no Brasil

ARNS, D. Paulo E. Brasil Nunca mais: Um relato para a história. 17. Edição. Petrópolis-RJ, Editora Vozes, 1986.

ARY, Zaíra. Masculino e feminino no imaginário católico: da Ação Católica à Teologia da Libertação. São Paulo-SP, Editora Annablume, 2000.

CHINIGO, Michael. Pio XII e os Problemas do Mundo Moderno. Tradução Pe. José Marins. São Paulo-SP, Edições Melhoramentos, 1960.

CRUZ, Maria A. Souza. A Guerra Fria e a Contracultura. Núcleo de estudos contemporâneos, Rio de Janeiro. Disponível em:

<http://www.historia.uff.br/nec/materia/grandes-processos/guerra-fria-econtracultura>. Acesso em 25 jan. 2012.

COELHO, Oscavú José. Entrevista concedida à Leuza Alves de Moura Silva. Goiânia, 07 de julho de 2004.

CUNHA, Alda Maria B. Entrevista. Goiânia, 02 de junho de 2015.

DALE, Frei Romeu O. P (org.). A Ação Católica brasileira. São Paulo-SP, Ed. Loyola/ Cepehib, 1985.

FILGUEIRAS, Otto. Revolucionários sem rosto: uma história da Ação Popular. Volume 1. São Paulo-SP, Instituto Caio Prado Jr., 2014.

LE GOFF, Jacques. Memória. In: Memória e História. Campinas: Unicamp, 1990, p.423-483.

HALBSWACHS, Maurice. Memórias Coletivas. SãoPaulo: Centauro, 2006.

LALEMANT G. C., Soeur Gabriel et al. A adjunta religiosa na JEC. Petrópolis-RJ, Editora Vozes, 1954.

LÖWY, Michael. Cristianismo da Libertação e Marxismo: de 1960 a nossos dias. In: RIDENTI, Marcelo; REIS FILHO; Daniel Aarão (Orgs.). Campinas-SP, Editora da Unicamp, 2007, p. 411-438.

MACHADO, Jackson Luiz P. Entrevista. Brasília, 29 de maio de 2015.

O POPULAR. Tradição de Luta no estado atraiu guerrilhas rurais. O Popular, Goiânia, 31 mar. 2014. Política. Disponível em: < https://www.opopular.com.br/noticias/politica/tradi\%C3\%A7\%C3\%A3o-de-luta-noestado-atraiu-guerrilhas-rurais-1.509813>. Acesso em: 26 jul. 2020.

POLLAK, Michael. Memória, esquecimento, silêncio. Revista Estudos Históricos, Rio de Janeiro, v. 2, n. 3, 1989, p. 3-15. Disponível em 


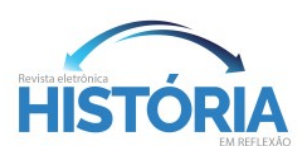

Dossiê: Ensino de História, História das Mulheres e Desigualdades Sociais no Brasil <http://bibliotecadigital.fgv.br/ojs/index.php/reh/article/view/2278/1417>. Acesso em 31 Jul. 2020.

REIS FILHO, Daniel A.; SÁ, Jair F. Imagens da Revolução: documentos políticos das organizações clandestinas de esquerda dos anos 1961-1971, 2. edição, São Paulo-SP, Expressão Popular, 2006.

ROSA, Eliana C. Universidade e sociedade: um estudo descritivo da inserção universitária em especial das mulheres no Brasil. Revista de iniciação e formação docente (2), Uberaba-MG, Grupo de Estudos e Pesquisas em Análise do Discurso, Leitura e Escrita (GEPADLE)/UFTM, 2015/2016, pp. 1-12.

SAFFIOTI, Heleieth. A mulher na sociedade de classes. 3 ed. São Paulo-SP, Expressão Popular, 2013.

SOFIATI, Flávio M. Juventude Católica: O novo discurso da Teologia da Libertação. São Carlos-SP, Editora Edufscar, 2012.

STEVENS, Evelyn P. Marianismo: la outra cara del machismo em Latino-América. In: PESCATELO, Ann (coord). Hembra y macho em Latino-América: Ensaios. México, Editora Diana, 1977.

SCHULTZ, Adilson. Aspectos teológicos essenciais para o diálogo ecumênico e inter-religioso. Revista Tecer, Belo Horizonte, v. 6, n. 10, mai. 2013, pp. 97-107.

SILVA, Hamilton Pereira. Prefácio para uma vida em curso. In: AZEVEDO, Ricardo. Por um triz: memórias de um militante da AP. São Paulo-SP, Plena Editorial, 2010, pp. 3-9.

SILVA, Uassy G. Entrevista. Pirenópolis, 07 de fevereiro de 2015.

TEIXEIRA, Gilberto Franco. Entrevista. Goiânia, 30 de janeiro de 2015.

VIEIRA, Euler Ivo. Entrevista. Goiânia, 28 de abril de 2015 